Pak. j. sci. ind. res. Ser. A: phys. sci. 2018 61A(3) 132-137

\title{
Assessment of Polycyclic Aromatic Hydrocarbons (PAHs) Present in the Atmosphere of Kot Lakhpat Industrial Estate of Lahore, Pakistan
}

\author{
Imran Kalim $^{a b *}$, Naseem Zahra ${ }^{b}$, Rubina Gilani ${ }^{a}$ and Liviu Mitu ${ }^{c}$ \\ ${ }^{a}$ Department of Chemistry, University of Engineering and Technology, Lahore-54890, Pakistan \\ ${ }^{b}$ Food \& Biotechnology Research Centre, PCSIR Laboratories Complex, Ferozepur Road, \\ Lahore-54600, Pakistan \\ 'Department of Natural Science, University of Pitesti, Pitesti, Romania
}

(received July 04, 2017; revised May 21, 2018; accepted June 07, 2018)

\begin{abstract}
The current research was conducted for the determination of concentrations of health hazardous PAHs (polycyclic aromatic hydrocarbons) in atmosphere which are among the dangerous identified organic pollutants. The atmospheric particulate matters were collected using high volume samplers from the industrial estate of Kot Lakhpat, Lahore, Pakistan. Average TPM (mg) of $\mathrm{PM}_{2.5}$ was 16.030 and $\mathrm{PM}_{10}$ was 144.300. The concentration of $\mathrm{PM}_{2.5}$ was $534.390 \mathrm{ng} / \mathrm{m}^{3} / \mathrm{h}$ and $12825 \mathrm{ng} / \mathrm{m}^{3} /$ day, while concentration of $\mathrm{PM}_{10}$ was $4180 \mathrm{ng} / \mathrm{m}^{3} / \mathrm{h}$ and $115440 \mathrm{ng} / \mathrm{m}^{3} /$ day. Gas chromatography was used for the quantification of 16 different PAHs. The mean total quantity of PAHs in air was $742.030 \mathrm{ng} / \mathrm{m}^{3}$ on the basis of total particulate matter. The mean concentration of dibenzo(a,h) anthracene was highest i.e. $123.370 \mathrm{ng} / \mathrm{m}^{3}$ with 10.660 $\mathrm{ng} / \mathrm{m}^{3}$ minimum and $236.080 \mathrm{ng} / \mathrm{m}^{3}$ maximum, concentrations. In the present study the PAHs concentrations are found to be very high, so, there should be proper air management system to control such health hazardous organic pollutants.
\end{abstract}

Keywords: organic pollutant, polycyclic aromatic hydrocarbon, gas chromatography, suspended particulate matter

\section{Introduction}

Polycyclic aromatic hydrocarbons (PAHs) are assembly of organic compounds which are abundantly present in the atmosphere of heavily populated areas which are having vehicular exhausts as well (Zheng, 2009). Some of these compounds have been designated as carcinogens, mutagens and teratogens in monographs of International Agency of Research on Cancer (IARC). So these may be lead to the carcinogenic, mutagenic and teratogenic behaviours and may also be increased severely when these toxic materials are present in highest amount in the respirable part of air. Many factors and activities are responsible for production and addition of PAHs into the atmosphere. The major source of polycyclic aromatic hydrocarbons is vehicular exhaust and power generation resulting from pyrolysis and incomplete incineration of fuels like diesel, petrol, coal, wood, furnace oil used in vehicles and power generation activities (Garban et al., 2002; Golomb et al., 2001; Halsall et al., 2001). The normal and compressed natural gas and liquid petroleum is also utilized in vehicles or domestic uses as well in the area under the study (PES,

*Author for correspondence; E-mail: ikalim@hotmail.com
2014). Another source or production activity of these compounds has also been introduced in recent years here in Lahore. This source is a huge utilization of electricity generators for electricity generation during load shedding, and this source affects consumption of organic fuels that are directly linked with enhanced production of PAHs. Various extremely simple hydrocarbons like $n$-butyl benzene, butadiene, styrene, acetylene and tetralin at a temperature of $700{ }^{\circ} \mathrm{C}$ forms some PAHs as a result of pyrolysis. The aromatic hydrocarbons formed as a result of pyrolysis include benzo[a]pyrene, benzo[k] fluoranthene and benzo[b] fluoranthene (Knize et al., 1999). The aromatic ring systems can also withstand the temperature of pyrolysis i.e., $700{ }^{\circ} \mathrm{C}$ while, $\mathrm{C}-\mathrm{H}$ and $\mathrm{C}-\mathrm{C}$ bonds of aliphatic compounds break suddenly into free radicals which then goes to recombination process (Hwang et al., 2003; Golomb et al., 2001). Presently, approximately 30 polycyclic aromatic hydrocarbons compounds and their derivatives have been revealed and identified having mutagenic and carcinogenic properties (Bjorseth and Ramdahl, 1985). PAHs may cause change in atmosphere due to physicochemical properties of these health 
hazardous compounds and on the basis of these changes PAHs behaviour can be predicted. In atmosphere semi volatile constituents of PAHs compounds are found which are in the form of adhered particles or in vapours (Basheer et al., 2003; Wingfors et al., 2001). PAHs with low molecular weight with 2-3 rings fused together are more water soluble, volatile and are frequently found in form of vapours, whereas, PAHs with higher molecular weight have numerous rings in fused form which are adhered with the particulate matter, particularly combustion soot (Smith et al., 1996). PAHs are present in the atmosphere of industrial regions as well as in rural areas (Garban et al., 2002; Gevao et al., 2000; Migaszewski, 1999; Kallenborn et al., 1998) because they may get simply transported over long distances and persist in the environment. Definitely their concentration is higher near the source of emission where intensities are highest. Sometimes due to different environmental factors like air pressure, temperature and humidity, the PAHs concentration changes in some peripheral areas also. During the last few years, many collected samples from environment like atmospheric particles have been analyzed for detection of PAHs (Aamot et al., 1996; Halsall et al., 1994).

The USEPA has presented life span cancer risk which is equal to 62 per 100000 persons exposed per $\mu \mathrm{g}$ of benzene released from soluble coke-oven emissions per $\mathrm{m}^{3}$ of ambient air. PAHs are carcinogens in nature, so many health risks may be associated to PAHs to much more extent (WHO, 2014).

The mospheric profile of PAHs concentrations in selected cities showed that the rural areas were dominated by pyrogenic release of PAHs, while the road traffic is the major contributor of PAHs increase in urban areas of Pakistan (Atif et al., 2016). The concentrations of PAHs were found highest in U.K. samples but in comparison with the hotter climate of Lahore, these PAHs are expected to be far higher in concentration (Smith et al., 1996). Oil combustion in industries, automobiles and fuel combustion during cooking are the major sources of prime PAHs. The variations at seasonal levels at diverse places have also been exposed in association to the thoroughness of higher PAHs levels (Gupta et al., 2006). As there is no data accessible on PAHs concentration in Industrial Estate of Kot Lakhpat Lahore, Pakistan, the main rationale of the present research was to obtain the valuable introductory information concerning the concentration of PAHs present in the total suspended particulate matters in the air of selected areas.

\section{Materials and Methods}

The samples of air were collected from Kot Lakhpat Industrial Estate, Lahore that is one of the busiest areas of Lahore with respect to traffic, business activities and different industries in peripheral areas (Fig.1). Three different times were selected for sample collection which contained first portion from school and office going time, the second portion was from schools off time and the industrial production peak time while the third portion was from the offices offtime, industrial and business activities peak time, all these tenures contain the maximum utilization of vehicles and electricity generators that enhance the exhaust containing more than $90 \%$ of the PAHs described in this study.

Analytical grade solvents like dichloromethane, methanol, chloroform, cyclohexane and ethanol (Merck; B.P.) were used in this experiment. Silica gel of 100 mesh (Merck) was used for column chromatography of PAH mixture. Silica gel was activated at $105^{\circ} \mathrm{C}$ for $24 \mathrm{~h}$ before use.

The weighed GFFs (glass fiber filters) were used for extraction using cyclohexane for $24 \mathrm{~h}$ in Soxhlet apparatus. PAHs were obtained by using cyclohexane as solvent. The extract having soluble organic matter (SOM) was concentrated and dried under nitrogen gas. This was further fractionated by chromatographic methods.

SOM was fractionated into aromatics, alkanes, nitrogen, Sulphur and Oxygen containing compounds and different polar compounds by column chromatography by using silica gel. Freshly activated silica $(30 \mathrm{~g})$ slurry in cyclohexane was packed in glass column for separation. The soluble organic matter present in cyclohexane was then poured onto column. The trifold volumes of cyclohexane were utilized to elute alkanes (Fraction I), 95:5 cyclohexane; dichloromethane bed volumes were used to separate aromatics (Fraction II), three bed volumes of methanol were used to elute NSOs (Fraction III) while polar compounds were separated with three fold volumes of chloroform (Fraction IV). Nitrogen purging was used to obtain concentrated fractions (Dilip, 2003).

Alumina was used to fractionate aromatic by column chromatography. Fractionation of aromatic hydrocarbons was done by glass column packed with alumina and eluted with $100 \%$ dichloromethane with nitrogen purging. GC-MS analysis was carried out for extracted 


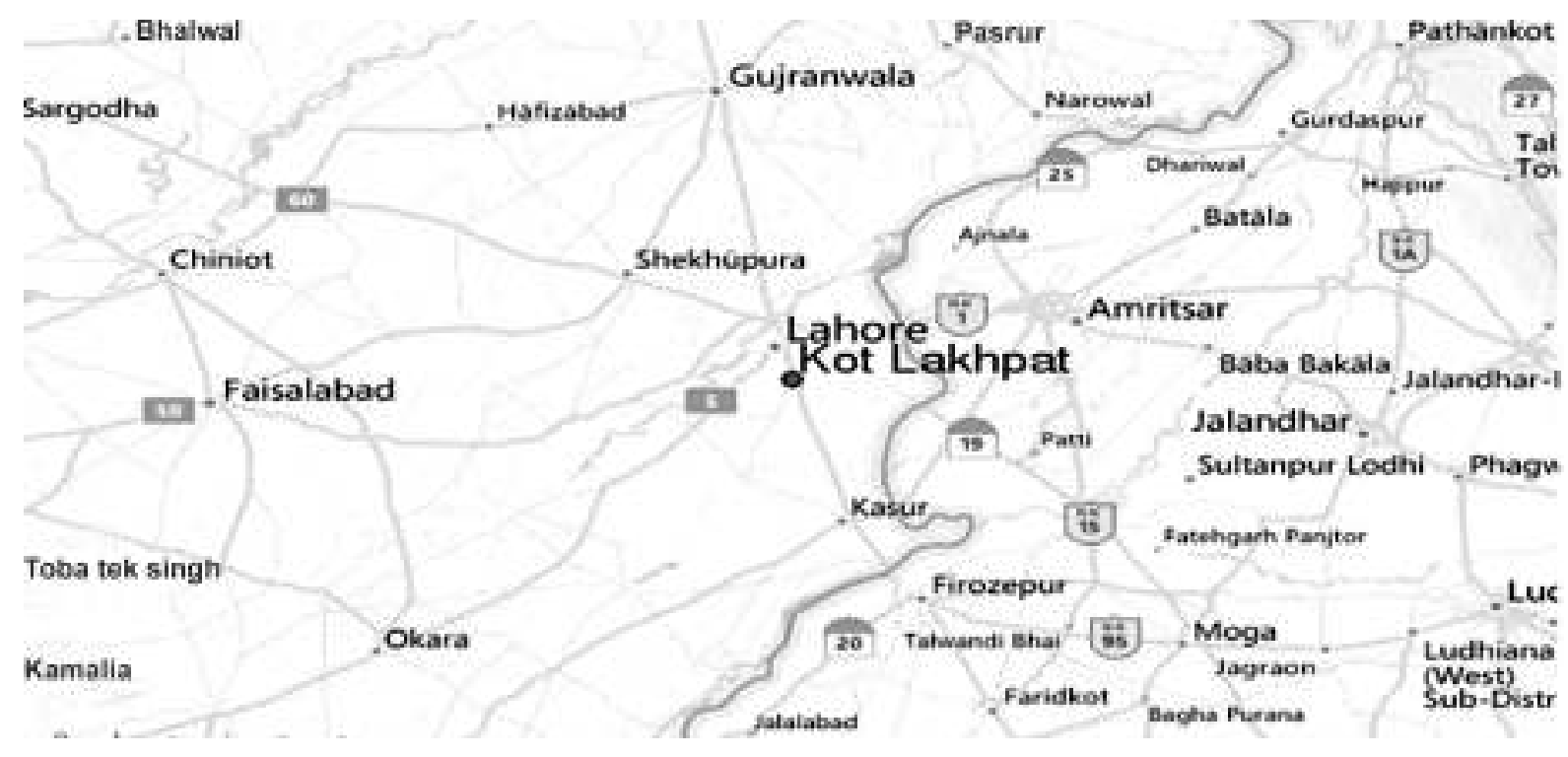

Fig. 1. Location of sampling area.

aromatics (Kalim et al., 2015). SPSS 17.0 (IBM SPSS Statistics 19) was used to apply one-way analysis of variance (ANOVA). Statistical analysis was performed to obtain the mean values for each PAH.

The GC-MS analysis was performed using a Mass Selective Detector (MSD) 5973 of Agillent Technologies interfaced to a 6890 gas chromatograph (GC) of Agillent Technologies as well equipped with a $30 \mathrm{~m}$ x $0.25 \mathrm{~m}$ ID capillary column coated with a $0.25 \mu \mathrm{m} 5 \%$ phenyl $95 \%$ methyl polysiloxane stationary phase (DB-5 MS, J \& W Scientific) was used for the analysis. $1 \mu \mathrm{L}$ of the aromatics fraction of standard and each sample $(1 \mathrm{mg} / \mathrm{mL}$ in $n$ hexane) was introduced into the split less injector using the micro syringe. The injector was operated at 280 ${ }^{\circ} \mathrm{C} / \mathrm{min}$ with initial and final hold times of 1 and $30 \mathrm{~min}$, respectively. The transfer line between the GC and the MSD was held at $310^{\circ} \mathrm{C}$. the MS source temperature was at $250{ }^{\circ} \mathrm{C}$. Data was acquired in full scan mode from 50 to 550 a.m.u., with the MS ionization energy $70 \mathrm{eV}$ and the electron multiplier voltage $1800 \mathrm{~V}$.

\section{Results and Discussion}

The present work entails the analysis of health hazardous organic pollutants PAHs in ambient air of Kot Lakhpat Industrial Estate. Daily average concentration TPM (total particulate matter) were calculated in three samples collected at three different times (morning, afternoon and evening) on the same day from Kot Lakhpat area, Lahore. 12 samples were collected and quantified for
16 PAHs. PAHs are absorbed on particulate matter and as higher the particulate matter, the higher will be the concentration of PAHs as well in the air samples. The results of total particulate matter $\left(\mathrm{PM}_{2.5}\right.$ and $\left.\mathrm{PM}_{10}\right)$ concentrations are given in Table 1.

Presence of particulate matter in air is problematic for the global environment. Penetration of solar radiation to the earth's surface is reported to be reduced by aerosol particles (particulate matter having diameter lesser than $2.5 \mu \mathrm{m}$ ). They have a close connection with augmented respiratory problems (Lee, 2000). The release of toxic particles and gases are mainly from power plants that burn fossil fuels in mega cities of Pakistan and automobile running on roads and industries (Manzoor et al., 2016). The concentrations of 16 PAHs in the particulate fractions of air samples of Kot Lakhpat area of Lahore are given in Table 2 as minimum, maximum and mean.

The mean concentration of dibenzo(a,h) anthracene was found to be highest among all PAHs i.e., $123.370 \mathrm{ng} / \mathrm{m}^{3}$

Table 1. Concentration of total particulate matter (TPM) from the Kot Lakhpat Industrial Estate in the $\mathrm{PM}_{2.5}$ and $\mathrm{PM}_{10}$ fractions of air

\begin{tabular}{llll}
\hline \multirow{2}{*}{ Particulate matter } & \multirow{2}{*}{ Average } & \multicolumn{2}{c}{ Concentration } \\
& TPM $(\mathrm{mg})$ & $\mathrm{ng} / \mathrm{m}^{3} / \mathrm{h}$ & $\mathrm{ng} / \mathrm{m}^{3} /$ day \\
\hline PM $_{2.5}$ & 16.030 & 534.390 & 12825.000 \\
PM $_{10}$ & 144.300 & 4180.000 & 115440.000 \\
\hline \hline
\end{tabular}


with $10.660 \mathrm{ng} / \mathrm{m}^{3}$ and $236.080 \mathrm{ng} / \mathrm{m}^{3}$, mean, minimum and maximum concentration, respectively.

Several works have verified that benzo[a]anthracene, benzo[a]pyrene and anthracene are produced by photolysis in the environment at extremely quicker rates. Aerosols are the most photoreactive components (typically for benzo[a] anthracene and benzo[a]pyrene) in Mediterranean which are decreased in urban and remote areas (Stone et al., 2010).

In under developed countries, a very small amount of data regarding PAHs carcinogenity has been acquired. In India incidence of PAHs were checked by taking samples from the atmospheres of urbanized areas like Lucknow (Bhargava et al., 2004); Mumbai (Kulkarni and Venkataraman, 2000); Nagpur (Vaishali, 1997) and Ahmedabad (Raiyani et al., 1993). The aerial PAHs concentrations in industrial areas i.e. 90.000 to 195.000 $\mathrm{ng} / \mathrm{m}^{3}$ were double than those of residential areas which had concentration of PAHs about 23.000 to 66.000 $\mathrm{ng} / \mathrm{m}^{3}$ (Pandit et al., 1996).

Several attempts were conducted indoor to scrutinize the differentiation between the levels of PAHs in various locations. In Lucknow, the PAHs concentration found

Table 2. Concentration of PAHs and related compounds at Kot Lakhpat industrial estate

\begin{tabular}{llll}
\hline \hline PAHs \& related & Minimum & Maximum & Mean \\
\cline { 2 - 4 } compounds & $\left(\mathrm{ng} / \mathrm{m}^{3}\right)$ & $\left(\mathrm{ng} / \mathrm{m}^{3}\right)$ & $\left(\mathrm{ng} / \mathrm{m}^{3}\right)$ \\
\hline Naphthalene & 5.980 & 25.740 & 15.990 \\
Acenephthylene & 10.140 & 18.720 & 12.480 \\
Phenathrene & 12.220 & 141.700 & 42.900 \\
Acenaphthene & 0.001 & 9.360 & 7.852 \\
Anthracene & 3.640 & 20.800 & 12.220 \\
Fluorene & 4.680 & 138.320 & 17.420 \\
Fluoranthene & 8.060 & 111.280 & 19.370 \\
Benzo(a) anthracene & 40.560 & 132.860 & 86.710 \\
Pyrene & 2.860 & 49.920 & 26.390 \\
Chrysene & 14.820 & 40.820 & 27.820 \\
Benzo (k) fluoranthene & 0.260 & 76.700 & 38.480 \\
Benzo (b) fluoranthene & 1.300 & 163.540 & 82.420 \\
Dibenzo(a,h) anthracene & 10.660 & 236.080 & 123.370 \\
Benzo(a) pyrene & 0.520 & 124.020 & 62.270 \\
Benzo (ghi) perylene & 16.120 & 94.380 & 55.250 \\
Indeno (1,2,3-c,d) pyrene & 0.003 & 31.980 & 15.990 \\
Benz (a) acridine & 1.300 & 40.200 & 18.500 \\
Dibenzo thiophene & 1.700 & 35.100 & 21.300 \\
5Methyl chrysene & 0.300 & 23.700 & 11.200 \\
3Methyl chrysene & 0.400 & 21.200 & 9.100 \\
1Methyl chrysene & 0.600 & 30.100 & 17.500 \\
Benzo (e) pyrene & 4.800 & 75.100 & 17.500 \\
Total & 140.920 & 1641.620 & 742.030 \\
\hline \hline & & & \\
\hline & & & \\
\hline & & &
\end{tabular}

to be predominantly elevated i.e., 2.230 to $46.070 \mu \mathrm{g} / \mathrm{m}^{3}$ indoor due to cow dung combustion however, low 0.860 to $4.760 \mu \mathrm{g} / \mathrm{m}^{3}$ than in ignition of liquefied petroleum gas or LPG (Bhargava et al., 2004). The breathing zones of Mumbai have higher concentrations of PAHs which increases further in winter season in comparison with summer season (Kulkarni and Venkataraman, 2000).

In a similar study conducted at Badami Bagh of Lahore city, Pakistan for the determination of concentrations of PAHs, the TSPM (total suspended particulate matters) were collected from air samples. It was found that the total mean concentration of PAHs was $746.600 \mathrm{ng} / \mathrm{m}^{3}$ and dibenzo(a,h) anthracene was in maximum concentration of $142.350 \mathrm{ng} / \mathrm{m}^{3}$ among all PAHs under investigation (Kalim et al., 2016). In Nagpur, the concentration of PAHs in air of industrial, commercial and residential zones was determined and found to be ranged from 125.000 to $195.000 \mathrm{ng} / \mathrm{m}^{3}$. The average quantity of PAHs in total was calculated in winter season for the successive 3 years i.e., 1992, 1993, and 1994 which was found to be $77.400 \pm 21.160 \mathrm{ng} / \mathrm{m}^{3}$ (Chattopadhyay et al., 1998; Vaishali et al., 1997).

Figure 2 depicts the worst scenario of PAHs presence in the air of Kot Lakhpat area of Lahore city. Dust particles with attached PAHs or PAHs vapours in the environment may cause different diseases in humans

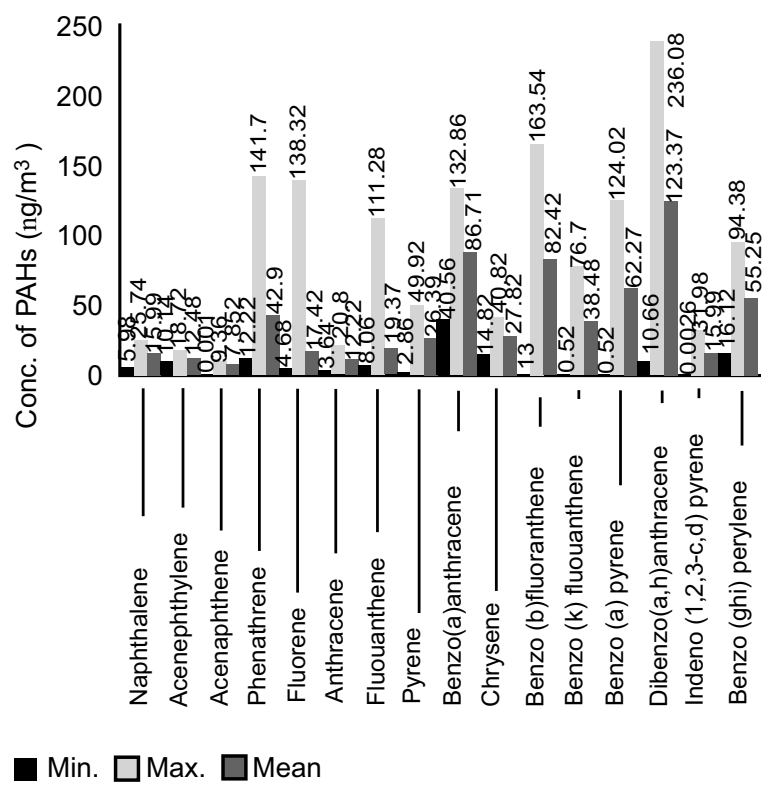

Fig. 2. Airborne PAHs minimum, maximum and mean concentrations at Kot Lakhpat Industrial Estate. 
who are exposed these carcinogenic PAHs particles. There should be appropriate plans to evaluate the amount of PAHs toxicity levels. Proper environmental control procedures should be adapted to monitor PAHs in air, water and food in order to safe human health from severe carcinogenity.

\section{Conclusion}

The study of PAHs in airborne particulate matter of the Kot Lakhpat area has shown that engine exhaust from heavy vehicles and ignition processes have enormously and hazardously added detrimental PAH organic particles in the air of Lahore. It has been concluded from the above study that the air of Kot Lakhpat area of Lahore has been immensely polluted with PAHs components, which are major health risk. The pollution due to particulate matter is affecting badly the entire environment which is highly alarming situation and is a matter of serious concern. The exposure of health hazardous PAHs should be properly controlled using effective air quality management system.

\section{References}

Aamot, E., Steinnes, E., Schmid, R. 1996. Polycyclic aromatic hydrocarbons in Norwegian forest soils; impact of long range atmospheric transport. Environmental Pollution, 92: 275-280.

Atif, K., Jabir, H.S., Jun, L., Gan, Z., Adeel, M., Riffat, N.M. 2016. Profile of atmospheric PAHs in Rawalpindi, Lahore and Gujranwala Districts of Punjab Province (Pakistan). Aerosol and Air Quality Research, 16: 1010-1021.

Basheer, C., Balasubramanian, R., Lee, H.K. 2003. Determination of organic micropollutants in rainwater using hollow fiber membrane/liquidphase microextraction combined with gas chromatography-mass spectrometry. Journal of Chromatography A, 1016: 11-20.

Bhargava, A., Khanna, R.N., Bhargava, S.K., Kumar, S. 2004. Exposure risk to carcinogenic PAHs in indoor-air during biomass combustion whilst cooking in rural India. Atmospheric Environment, 38: $4761-4767$.

Bjorseth, A., Ramdahl, T. 1985. Sources of emission of PAH. In: Handbook of Polycyclic Aromatic Hydrocarbons. A. Bjorseth and T. Ramdahl, (eds.) vol. 2, pp. 1-20, Marcel Dekker, New York, USA. Chattopadhyay, G., Samanta, G., Chatterjee, S., Chakraborti, D. 1998. Determination of particulate phase polycyclic aromatic hydrocarbons in ambient air of Calcutta for three years during winter. Environmental Technology, 19: 873-882.

Garban, B., Blanchoud, H., Motelay-Massei, A., Chevreuil, M., Ollivon D. 2002. Atmospheric bulk deposition of PAHs onto France: trends from urban to remote sites. Atmospheric Environment, 36: 5395-5403.

Gevao, B., Hamilton-Taylor, J., Jones, K.C. 2000. Towards a complete mass balance and model for PCBs and PAHs in a small rural lake, Cumbria UK. Limnology and Oceanography, 45: 881-894.

Golomb, D., Barry, E., Fisher, G., Varanusupakul, P., Koleda, M., Rooney, T. 2001. Atmospheric deposition of polycyclic aromatic hydrocarbons near New England coastal waters. Atmospheric Environment, 35: 6245-6258.

Gupta, A.K., Nag, S., Mukhopadhyay, U.K., 2006. Characterization of PM 10, PM 2.5 and benzene soluble organic fraction of particulate matter in an urban area of Kolkata, India. Environmental Monitoring and Assessment, 115: 205-222.

Halsall, C.J., Sweetman, A.J., Barrie, L.A., Jones, K.C. 2001. Modelling the behaviour of PAHs during atmospheric transport from UK to the Arctic. Atmospheric Environment, 35: 255-267.

Halsall, C.J., Coleman, P.J., Davis, B.J., Burnett, V., Waterhouse, K.S., Harding-Jones, P., Jones, K.C. 1994. Polycyclic aromatic hydrocarbons in UK urban air. Environmental Science \& Technology, 28: $2380-2386$.

Hwang, H.M., Wade, T.L., Sericano, J.L. 2003. Concentrations and source characterization of polycyclic aromatic hydrocarbons in pine needles from Korea, Mexico, and United States. Atmospheric Environment, 37: 2259-2267.

Kalim, I., Zahra, N., Fazeelat, T. 2016. Estimation of polycyclic aromatic hydrocarbons (PAHs) present in the atmosphere of urbanized region of Badami Bagh in Lahore, Pakistan. Pakistan Journal of Science, 68: 139-145.

Kalim, I., Zahra, N., Nisa, A., Hina, S., Fazeelat, T. 2015. Determination of polycyclic aromatic hydrocarbons in atmosphere of the city of Lahore, Pakistan. Research Journal of Chemical Sciences, 5: 1-6.

Kallenborn, R., Oehme, M., Wynn-Williams, D.D., Schlabach, M., Harris, J. 1998. Ambient air levels and atmospheric long-range transport of persistent organochlorines to Signy Island, Antarctica. Science 
of the Total Environment, 220: 167-180.

Knize, M.G., Salmon, C.P., Pais, P., Felton, J.S. 1999.

Food heating and the formation of heterocyclic aromatic amine and polycyclic aromatic hydrocarbon mutagens/carcinogens. In: Impact of Processing on Food Safety, pp. 179-193, Springer US.

Kulkarni, P., Venkataraman, C. 2000. Atmospheric polycyclic aromatic hydrocarbons in Mumbai, India. Atmospheric Environment, 34: 2785-2790.

Lee, H. K. 2000. Polycyclic aromatic hydrocarbons. Environmental Health Perspect, 106: 792.

Manzoor, M., Khan, A.H.A., Ullah, R., Khan, M.Z., Ahmad, I. 2016. Environmental epidemiology of cancer in South Asian population: risk assessment against exposure to polycyclic aromatic hydrocarbons and volatile organic compounds. Arabian Journal for Science and Engineering, 41: 2031-2043.

Migaszewski, Z.M. 1999. Determining organic compound ratios in soils and vegetation of the Holy Cross MTS, Poland. Water, Air, Soil Pollution. III, 123-138.

PES, 2014. Environment, Pakistan Economic Survey. 2013-2014. Ministry of Finance. Goverment. of Pakistan. Available at: http://www.finance.gov.pk/ survey/chapters_14/16_Environment.pdf

Pandit, G.G., Sharma, S., Mohan, R.A.M., Krishnamoorthy, T. M. 1996. Chromatographic methods for the estimation of polycyclic aromatic hydrocarbons in atmospheric particulates. $5^{\text {th }}$ National Symposium on Environment, Calcutta, India, 8 Feb. 28-1 March,
133-136.

Raiyani, C.V., Jani, J.P., Desai, N.M., Shah, S.H., Shah, P.G., Kashyap, S.K. 1993. Assessment of indoor exposure to polycyclic aromatic hydrocarbons for urban poor using various types of cooking fuels. Bulletin of Environmental Contamination and Toxicology, 50: 757-763.

Smith, D. J.T., Roy, M.H., Luhana, L., Casimiro, A.P., Castro, L. M., Mohammad, N. T., Hayat, S., Quraishi, T. 1996. Concentrations of particulate airborne polycyclic aromatic hydrocarbons and metals collected in Lahore, Pakistan. Atmospheric Environment, 30: 4031-4040.

Stone, E., Schauer, J., Quraishi, T.A., Mahmood, A. 2010. Chemical characterization and source apportionment of fine and coarse particulate matter in Lahore, Pakistan. Atmospheric Environment, 44: 1062-1070.

Vaishali, R., Phadke, K.M., Thakre, R., Hasan, M.Z., 1997. PAHs in respirable particulate matter in Nagpur city. Journal of the Indian Association for Environmental Management, 24: 11-16.

WHO, 2014. Ambient air quality and health. Fact sheet N 313. WHO media Centre. Available at: http:// www.who.int/mediacentre/factsheets/fs313/en/. Wingfors, H., Sjödin, Å., Haglund, P., BrorströmLundén, E. 2001. Characterization and determination of profiles of polycyclic aromatic hydrocarbons in a traffic tunnel in Gothenburg, Sweden. Atmospheric Environment, 35: 6361-6369. 